\title{
Filosofia como estratégia ${ }^{1}$ \\ Philosophy as strategy
}

\author{
FELIPE LUIZ ${ }^{2}$
}

No bojo de pesquisa ora em curso, que envolve as vicissitudes da noção de filosofia da guerra, apresentaremos um conceito de filosofia entendida ela mesma como estratégia, talvez, mesmo, como a forma superior mais bem acabada de estratégia. Como é de amplo conhecimento, a doutrina militar concebe a distinção entre tática e estratégia, entendendo a última como objetivo de longo prazo, sendo a primeira as etapas ou movimentos necessários para alcançá-lo, circunscrita, portanto, a prazos diminutos relativamente à estratégia. $\mathrm{O}$ dito popular "para fazer a limonada é preciso espremer os limões" expressa clara e simplificadamente a referida distinção: o objetivo estratégico "fazer a limonada" demanda que determinadas ações de caráter tático sejam levadas a cabo, no caso, "espremer os limões".

Sustentamos que a filosofia é de natureza tal que suas formulações são ou aspiram à apoditicidade e ao holismo, objetivando exaurir o ser da coisa, tendo, ademais, marcado caráter teorético, valendo-se do material empírico em ocasiões raras, por vezes contestáveis; para nós, são estas as principais características que assinalam a filosofia como estratégia, embora não sejam as únicas e, mesmo, as mais decisivas.

Não será surpresa, para os conhecedores de alguma literatura filosófica, a apresentação desta disciplina como tendo efeitos de longo prazo, pelas características que a vincam e pelos temas os quais a filosofia toma para si. A Filosofia Política, por exemplo, busca conceituar os traços mais gerais da vida em sociedade, os motivos que levaram os seres humanos a assim fazê-lo, o que é governo e quais seus limites, etc. Outro exemplo, este mais candente pela presunção é o da Lógica, que intenta apresentar quais, na miríade de argumentos plasmáveis, são válidos e quais não. Ao buscar apresentar o conceito, a filosofia enquadra não somente tudo quanto veio-ser e tudo quanto é-em-sendo; ela também determina o vir-a-ser das coisas, como se darão os desdobramentos de um objeto específico de

\footnotetext{
${ }^{1}$ O texto foi escrito para o "Simpósio Antônio Trajano", da UNESP-Marília, em 2014, cujo tema era "O que é filosofia?". O professor Trajano, docente desta casa por décadas, dedicou-se a fomentar a reflexão autoral nos discentes e a necessidade de filosofarmos em primeira pessoa. Eis o espírito do texto que segue.

${ }^{2}$ Bacharelando em Filosofia na FFC-UNESP/Marília. Foi bolsista PIBIC-CNPQ atuando no tema Filosofia Francesa Contemporânea (Michel Foucault) e epistemologia política da psiquiatria. Posteriormente, dedicou-se a estudar as relações entre o pensamento de Foucault e o anarquismo. Atualmente, estuda as vicissitudes da noção de "filosofia da guerra", com ênfase em Filosofia Antiga. Todas as pesquisas empreendidas resultaram em artigos publicados. E-mail: gumapoldo51@yahoo.com.br.
} 
reflexão, exemplificado nas instituições políticas ou nos argumentos: neste movimento, é como se a filosofia fizesse a análise da correlação de forças para determinar as condições e os ladrilhos de sua rota rumo à vitória, rumo à sua consecução. Em muitos casos, os malabarismos teóricos chegam a sangrar a carne da coisa com as baionetas do conceito a fim de enformá-lo; talvez porque o conceituar filosófico seja uma subsunção teórica da coisa ao conceito. Em arrebate, parece-nos que toda filosofia tem de ser meta...

Ora, a estratégia pressupõe um estrategista ou, para mantermo-nos no mesmo horizonte de espelhos e alusões, se a filosofia é uma estratégia, para qual exército ela trabalha e, também, quais seriam seus objetivos finais? Outra questão que se desfia de nossas posições é: neste curto ensaio filosófico, qual o nosso objetivo estratégico enquanto formuladores, pois a metafilosofia, talvez, não seria, esta sim, a estratégia da estratégia, determinação geral da determinação geral - e assim sucessivamente, no ad infinitum do pensamento se dobrando sobre si? É nesta tropa de argumentos, onde a cobra come o rabo, e o tiro parece sair pela culatra, que marcharemos.

"Bater por partes" é o nome de uma velha estratégia, de nome autoexplicativo, a qual também lançaremos mão. De saída, portanto, são necessárias indicações mais precisas. Nós não caracterizamos esta ou aquela filosofia como estratégia, mas o conjunto da filosofia, o que significa que a própria forma pela qual a tradição filosófica vicejou e segue sendo, faz parte de uma estratégia. A primeira dificuldade que se esboçaria seria de ordem enciclopédica, posto que afirmação tão grandiloquente pareceria demandar que seu autor conhecesse a totalidade das reflexões filosóficas já desenvolvidas e que, tal qual calculadora, mostrasse sua soma como integrantes desta mesma estratégia. Contudo, desde nosso ponto de vista, se há um conceito "filosofia", tal somente pode dever-se a traços comuns que, desta forma, permitem este mesmo conceito. Ademais, a descrição das distintas filosofias não é filosofia, mas história da filosofia, algo que o professor Antônio Trajano, da UNESP-Marília, tantas vezes expressou; o mesmo raciocínio aplica-se, também, às relações entre economia e história econômica (dentre outras ciências e suas respectivas histórias): grandes historiadores da economia não produziram sequer uma linha de teoria econômica. Enfim, descrever feitos não é o mesmo que realizálos.

Seria, pois, necessário encontrar o fio da meada que nos conduzisse, em filosofando, ao cerne da filosofia, e, desta feita, encontrar o que buscamos. Martin Heidegger propõe uma pista interessante: a situação do surgimento da filosofia, que o nome, grego, revela (HEIDEGGER, 1957). A filosofia surge na Grécia Antiga, em contraposição às formas tradicionais de explicação do mundo, como a religião: em filosofia, não "se crê por ser absurdo", sendo mister justificar o que se defende. Paralelamente, o mundo grego também dava lugar ao desenvolvimento da 
matemática, da poesia e da história, sendo estas, as quais podem-se juntar muitas outras, heranças específicas da Grécia.

Aristóteles afirma que a filosofia surgiu do ócio, o que nos dá especiais indicações sobre a estrutura social, o mundo do qual decorre o pensamento filosófico (ARISTÓTELES, 980a-1093b). O contexto de surgimento de um pensamento grava-se nele; o pensamento responde ao mundo que o circunda, e mesmo as metafísicas mais abstratas podem ser situadas em uma correlação de forças, como mostraremos. Em um mundo de fronteiras fluidas e constantes invasões, muitas das quais marcam a península balcânica, as tribos invasoras, com conhecimentos técnicos diferentes, certamente marcaram as diferentes maneiras de filosofar, e o próprio aparecimento de algo como um projeto filosófico.

Ademais, variados autores, dentre os quais Platão e Aristóteles, afirmam que a filosofia surge de uma especial disposição de espírito traduzida por vezes como espanto, noutras por maravilhamento, também por admiração. No âmbito específico daquele que filosofa, a filosofia surge de uma reação, de um questionamento frente à existência do que existe. Acrescentamos: necessidade de responder: "por que o que existe existe?", de dar sentido, em acepção ampla de significado, ao fato da existência do existente.

Três pontos, pois: contraposição a uma explicação mitológica em benefício de argumentos e provas conceituais, aparecimento tributário de variadas formas de dominação e espanto frente à existência do existente. Chamaremos este conjunto de "retaguarda" do problema.

Doutro lado, há um "flanco" amplo. Variadas sociedades antigas, e também contemporâneas, são reguladas por princípios religiosos, em algumas, mesmo, cada menor aspecto da vida está ritualizado segundo preceitos divinos. Em algumas, toda a vida de pessoas que sequer vieram à lume já está definida desde sempre, para sempre, caso de sociedades de castas. Noutras tantas, os governantes são ungidos por forças divinas, sendo sua vontade equivalente a do deus, que criou humanos. Crescentemente, desde meados do século XVIII, variadas sociedades se laicizam, quer dizer, as formas de organização social teocráticas dão lugar a outras, burocráticas, organizadas segundo outros princípios, que muitas vezes fazem questão de honra reivindicar-se racionais, foram concebidos por filósofos os quais, não raras vezes, também foram políticos. Que a cicuta de Sócrates não nos deixe esquecer da animosidade entre filosofia e tradições.

Noutro "flanco", a questão que se afigura é que a sociedade global crescentemente marcou-se pelo avanço da ciência contemporânea, especialmente da técnica. Somente é possível que pensemos em sociedade global pelo avanço da cartografia; somente podemos nos reunir aqui, hoje, migrantes, imigrantes e frutos da diáspora negra, pelos avanços desta mesma ciência. É impossível negar que a 
ciência contemporânea decorre do projeto filosófico, como tantas vezes salientouse, e que, filha dileta, a ciência deu cabo de certas intenções de sua idosa genitora.

A infantaria do problema, por assim dizer, tem a ver com o fim do animismo, tema que retoma o já dito sobre o surgimento da filosofia. Como se sabe, o pensamento anímico concede a parcelas da natureza, ou ao seu conjunto, poderes que influem no fluxo do mundo, e o mundo, ele mesmo, emerge como portador de uma vontade. É precisamente o contrário de explicar a ocorrência de fenômenos segundo uma casualidade descritível, por vezes codificável em leis matemáticas ou da natureza; é o contrário de querer descrever o funcionamento do mundo - que não se dá segundo as vicissitudes da vontade, mas, antes, preferencialmente, segundo uma regularidade passível de assim ser expressa.

De conjunto, parece-nos, pois, que esse "exército filosófico" guerreou contra um mundo explicado pela fé, imbuído de forças volitivas naturais, organizados segundo preceitos religiosos revelados, engendrando coisa em tudo distinta. Engendrando a sociedade moderna progressivamente global.

Engana-se quem pensa que a doutrina militar concebe a guerra como restrita aos campos de batalha. O objetivo das Forças Armadas é defender, assegurar e majorar o Poder Nacional, em suas variadas expressões, dentre as quais uma expressão militar, mas, também, uma expressão econômica, expressão científicatecnológico, psicossocial, etc. A doutrina militar contemporânea, erigida sob variada reflexão acerca de diferentes elaborações teóricas sobre a guerra, e, também, sobre experiência bélicas passadas, tem claro que guerra significa não só a submissão do adversário pela força, como também a dominação de variados aspectos das formas de vida nas quais ele insere-se, inclusive as de produção e reprodução da vida, como também àquelas relativas às formas de significar o mundo.

Em termos estratégicos, portanto de longo-médio prazo, o fazer majorar outras expressões do Poder Nacional parece até mais efetivo que o mero medo que a força das armas provoca, concomitantemente à contraofensiva que sempre espreita os armados, redundando em um clima de medo recíproco. As demais expressões do Poder Nacional têm impactos mais duradouros, de transformação mais difícil que aqueles possibilitados pelas armas.

Se a estratégia sempre implica na intenção ou em procedimentos que buscam determinar o devir, segundo certos objetivos, ela parece sempre circunscrita a aspectos do mundo, por exemplo, uma estratégia de marketing de um produto, ou uma estratégia de dominação de um país vizinho, etc. Será que, contudo, não existiria uma forma suprema de estratégia, que buscaria determinar não este ou aquele aspecto, mas o próprio conjunto do existente em sua existência e vir-a-ser? Trabalhando em uma variação nietzschiana, a forma suprema de estratégia será 
aquela que não só intentar como também conseguir alterar as maiores plagas do que há, do que foi e do que virá-a-ser.

Universalidade, totalidade, necessidade. Conceitos caros à tradição filosófica, seja de modo patente, seja de modo velado. Aliás, mais do que conceitos: objetivos. Por vezes, limites entre o que seria apontado como filosófico e o que não preencheria os requisitos para tanto. Se o conhecimento em sua raiz é sempre político, tal qual quer Michel Foucault (FOUCAULT, 2005a), e todo sentido é, pois, ato de guerra, que dizer de proposições que buscam significar não isto ou aquilo, mas todo o isto e todo aquilo? Não serão a maneira mais insidiosa de fazer a guerra? Não será a estratégia mais poderosa e eficaz, visto que alterou todo o planeta?

Esta estrategiosofia ${ }^{3}$ não quer dizer que há um estrategista que a concebeu, à moda do gênio maligno cartesiano, digamos, um gênio estrategista operando na sombra do mundo; trata-se de uma estratégia sem sujeito, como concebeu Foucault (FOUCAULT, 2007), quer dizer, em suas consequências não tributária de uma filosofia do sujeito (como a fenomenologia), porque as conseqüências ultrapassam a volição do sujeito. Proposições do gênero que são as filosóficas, que buscam determinar o que é, têm conseqüências de longo prazo; proferi-las, propagá-las já implica conseqüências de longo prazo, pela sua própria estrutura. Responder a esta tradição é entrar na luta tática, com possíveis desdobramentos estratégicos, da maneira como essa estratégia seguirá se desenrolando.

Desmistificando o mundo, organizando sociedades em torno de princípios burocráticos racionais, e deixando agir o obus da ciência crescentemente técnica, que quer alterar não a totalidade do ente, mas a entidade de entes específicos; o que objetiva a filosofia? Para onde aponta? Não será para o fim do homem, ou, antes da humanidade, em duplo sentido, em benefício de seres que existem segundo regras, procedimentos, organizações e objetivos não mais codificados segundo o mito, mas sob o império da razão? Carne e máquina se confundindo e o fim da humanidade: o advento da maquinidade. A filosofia intentaria, portanto, levar as últimas consequências os objetivos de conhecimento de quem a criou, dando à luz seres capazes de romper a finitude da vida humana, e, assim, significar e conhecer a totalidade, ajudado por uma memória virtualmente infinita e corpos os quais trocase conforme passa o tempo? Será que as anunciadas formas de superação da humanidade ou de sua sociabilidade não estavam em germe desde o início, nas primeiras reflexões de Tales? Pensada desta forma, pode-se dizer que a filosofia aplica a clássica manobra de "pinça", cercando o adversário, a fim de massacrá-lo; tendo até hoje, portanto, criado as condições para seu objetivo primevo: o conhecimento da totalidade do ser. Se a filosofia será vitoriosa ou não, decorrerá dos embates que tem pela frente. $\mathrm{E}$ os resultados destes embates somente virão conforme eles se desenrolem.

\footnotetext{
${ }^{3} \mathrm{Ou}$ a filosofia entendida como estratégia.
} 


\section{Referências}

ANAXIMANDRO DE MILETO; Doxografia, fragmentos, crítica moderna in SOUZA, J. C. de et alii.. Os pré-socráticos. 2. ed. São Paulo: Abril Cultural, 1978.

ARISTÓTELES. Metafísica, Tradução Edson Bini, Bauru, SP: Edipro, 2006.

BEAUFRET, J.; Introduction a une lecture du poème de Parménide in Le poème de Parménide. Paris: PUF, 1955.

BERGE, D.; O logos heraclítico: introdução à leitura dos fragmentos. Rio de Janeiro: Instituto Nacional do Livro/MEC, 1969.

CASTRO, E. Vocabulário de Foucault. Tradução Ingrid Muller Xavier. Belo Horizonte: Autêntica, 2009.

CRESSON, A. A filosofia antiga. Tradução de Beatriz Moura. 2. ed. São Paulo: Difusão Européia do Livro, 1960.

FOUCAULT, M. A verdade e as formas jurídicas. Tradução de Eduardo Moraes e Roberto Machado. Rio de Janeiro: NAU, 2005a.

. Em defesa da sociedade. Tradução de Maria Ermantina Galvão. São Paulo: Martins Fontes, 2005b.

. Microfisica do poder. Tradução de Roberto Machado. Rio de Janeiro: Graal, 2007.

. Nietzsche Freud Marx; Theatrum Philosophicum. Tradução Jorge Lima Barreto SP:

Princípio, s/d, disponível em http://pt.scribd.com/doc/22082432/Foucault-Michel-

Nietzsche-Freud-e-Marx consultado em 28 de novembro de 2017.

GLULIEMINI, J. P. Le grec ancien. Poitiers: Assimil, 2003.

HEGEL, G. W. F. Introdução à história da filosofia. Tradução de E. C. Silva. São Paulo: Hemus, 1983.

. Preleções sobre a história da filosofia. Tradução de Ernildo Stein in SOUZA, J. C. de et alii. Os pré-socráticos. 2. ed. São Paulo: Abril Cultural, 1978.

HEIDEGGER, M. Carta sobre o humanismo. 3. ed. Tradução de Pinharanda Gomes Lisboa: Guimarães Editores, 1987.

. Essais et conférences, Tradução André Préau. Paris: Gallimard, 1958.

. Introdução à Metafísica. Tradução de Emmanuel Carneiro Leão. 2. ed. Rio de

Janeiro: Tempo Brasileiro, 1969.

Qu'est-ce que ce - la philosophie. Tradução de Kostas Axelos e Jean Beaufret. Paris:

Gallimard, 1957.

HERÁCLITO. Doxografia, fragmentos, crítica moderna in SOUZA, J. C. de et alii. Os présocráticos. Tradução de José Cavalcante de Souza. 2. ed. São Paulo: Abril Cultural, 1978.

Fragmentos Diels-Kranz in BERGE, D.; O logos heraclítico: introdução à leitura dos fragmentos. Rio de Janeiro: Instituto Nacional do Livro/MEC, 1969.

Fragmentos contextualizados. Tradução de Alexandre Costa. Lisboa: Imprensa Nac_ional-Casa da Moeda, 2005.

LIBERA, A. de. A filosofia medieval. Tradução de Lucy Magalhães. Rio de Janeiro: Jorge Zahar, 1990.

LUIZ, F. A filosofia, a dominação. In Revista Espaço Livre, s/l, vol. 8, num. 16, jul. dez. 2013 a. 
. A relação entre verdade e política em Foucault. In: Filogênese, Marília-SP, n. 1, vol. 1, 2008.

. Foucault genealogista: a guerra como modelo analítico das relações de poder, Cadernos da Graduação, Campinas-SP, v. 1, p. 145-152, $2010^{\underline{a}}$.

. O conceito de saber na epistemologia política de Michel Foucault, Revista de Iniciação Científica da FFC, Marília-SP, Vol. 10, n. 2, 2010b, disponível em http://www2.marilia.unesp.br/revistas/index.php/ric/article/viewFile/331/379

Precisões sobre o conceito de filosofia da guerra, Filogênese, Marília-SP, vol. 7, no. 2, 2014b disponível em http://www.marilia.unesp.br/Home/RevistasEletronicas/FILOGENESE/2_felipeluiz.pdf. . Sentido da vida como determinação política. Marília: 2013b, mim.

NIETZSCHE, F. A filosofia na época trágica dos gregos. Tradução de Rubens Rodrigues Torres Filho, in SOUZA, J. C. de et alii. Os pré-socráticos. 2. ed. São Paulo: Abril Cultural, 1978.

O nascimento da tragédia ou helenismo e pessimismo. Tradução de Jacó Guinsburg. São Paulo: Cia. das Letras, 1999.

PESSANHA, J. A. M. Do mito à filosofia in SOUZA, J. C. de et alii. Os pré-socráticos, 2. ed. São Paulo: Abril Cultural, 1978.

PARMÊNIDES. Le poème de Parménide. Tradução Jean Beaufret. Paris: PUF, 1955.

PRATES E SILVA, R. C. B. A justiça cósmica (um estudo sobre Anaximandro de Mileto), Tese de Livre-docência, Araraquara: FCL-UNESP, 1992, 423p.

SAINT-PIERRE, H. Política armada - fundamentos da guerra revolucionária. São Paulo: EDUNESP, 1999.

SCHOPENHAUER, A. Metafísica do belo. Tradução de Jair Barboza. São Paulo: EDUNESP, 2003.

SOUZA, J. C. de et alii. Os pré-socráticos. 2. ed. São Paulo: Abril Cultural, 1978.

Submissão: 11.07.2017 / Aceite: 12. 08. 2017 